\title{
Ocena wiarygodności badania densytometrycznego
}

\section{Evaluation of credibility test densitometry}

\section{Streszczenie}

W pracy dokonano oceny wiarygodności badania densytometrycznego do określenia wysokości wad spoiny. Dokonano pomiarów gęstości optycznej obrazów i przeprowadzono niezbędne obliczenia wynikające z obowiązującej normy. Wykazano dużą niejednoznaczność wyników i obliczeń. $\mathrm{Na}$ podstawie analizy, z uwagi na dużą rozbieżność wyników, wykazano jak ważne jest właściwe planowanie badań nieniszczących w kontroli jakości złączy spawanych oraz postępowanie w tych badaniach.

Słowa kluczowe: badania radiograficzne; badania densytometryczne; wiarygodność badań

\begin{abstract}
In this paper assesses the credibility of densitometry to determine the amount of defects in the weld. Measurements were made of optical density images and the necessary calculations were performed under the applicable standard. Demonstrated great ambiguity of the results and calculations. Based on the analysis, due to the large discrepancy results demonstrated the importance of proper planning nondestructive testing quality control of welded joints and procedure in these studies.
\end{abstract}

Keywords: radiographic testing; densitometry testing; credibility test

\section{Wstęp}

Wszelkiego rodzaju konstrukcje stalowe bardzo często są wykonywane i montowane technikami spawalniczymi, dlatego jakość wykonania spoin ma duże znaczenie. Uszkodzenia złączy spawanych wiążą się z wielkością i rodzajem naprężeń, własnościami materiałów oraz z wymiarami niezgodności spawalniczych.

Ocenę jakości spoiny można dokonać metodami niszczącymi oraz nieniszczącymi. Oczywistym jest, że w warunkach wytwarzania i eksploatacji dąży się do stosowania metod nieniszczących. Metodami tymi można określać tylko przybliżone wymiary geometryczne niezgodności spawalniczych. Jednak dzięki takiemu działaniu zabezpieczamy konstrukcję przed niespodziewanym uszkodzeniem złącza zapoczątkowanym od wad w spoinie. Obecność niezgodności w złączach nie jest rzeczą niezwykłą, o ile ich rodzaj i wielkość nie zagrażają bezpieczeństwu konstrukcji.

Do wykrywania oraz określania niezgodności spawalniczych wykorzystuje się wiele różnych metod badań nieniszczących, np.: wizualne, penetracyjne, magnetyczno-proszkowe, radiograficzne, ultradźwiękowe, prądami wirowymi. W zależności od odpowiedzialności i klasy konstrukcji dobiera się poszczególne metody defektoskopii. Do oceny jakości złączy spawanych można przyjąć wybraną pojedynczą metodę lub ich zespół (kombinację) składający się z kilku, najczęściej dwóch niezależnych metod

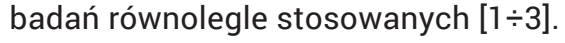

Przy wyborze metod badań nieniszczących oraz poziomów (klas) badań, należy uwzględnić następujące czynniki $[2 \div 6]$ :

- metody spawania,

- materiał podstawowy, materiał dodatkowy, stan jego obróbki,

- rodzaj złącza i jego wymiary,

- kształt elementu (dostępność, stan powierzchni, itp.),

- poziomy jakości,

- spodziewane rodzaje niezgodności spawalniczych i ich usytuowanie.

Za podstawowe metody badań nieniszczących - uznawane w normach i przepisach - przyjmuje się: badania radiograficzne (RT) i ultradźwiękowe (UT) $[2,7,8]$. Powszechność stosowania badań radiograficznych wynika z możliwości jednoczesnego badania dużych powierzchni oraz z łatwości wykrywania wewnętrznych niezgodności. Jednak istotnymi wadami tych badań są: duże koszty, zapewnienie dostępu z obu stron spoiny, istotny jest kierunek nieciągłości liniowych oraz wymagane są bardzo duże kwalifikacje personelu. Wykryte wskazania nieciągłości w wyniku badań RT są ocenianie na zdjęciu radiograficznym według określonych kryteriów przez osoby posiadające odpowiednie uprawnienia $[2,3,7,9]$.

Jednym $z$ badań radiograficznych jest badanie densytometryczne, które choć jest znormalizowane nie jest często stosowane w praktyce przemysłowej. W pracy

dr hab. inż Maciej Matuszewski; mgr inż. Mirosława Wiśniewska - Uniwersytet Technologiczno-Przyrodniczy w Bydgoszczy. Autor korespondencyjny/Corresponding author: matus@utp.edu.pl 
dokonano oceny wiarygodności tego badania dotyczącego określenia wysokości wad spoiny na podstawie gęstości optycznej obrazu.

\section{Charakterystyka badań densytometrycznych}

Badania densytometryczne polegają na pomiarze gęstości optycznej, która jest miarą zaczernienia tła radiogramu (materiału rodzimego), obrazu wzorca defektometrycznego lub obrazu wady na radiogramie. Gęstość optyczną mierzy się za pomocą densytometru, którego działanie polega na przepuszczeniu przez badaną próbkę wąskiej wiązki światła, która następnie przechodząc przez przetwornik energii świetlnej, stanowiący odbiornik fizyczny promieniowania (np. ogniwo fotoelektryczne lub termoelektryczne), zamieniana jest w energię elektryczną. Stosunek prądów fotoelektrycznych w miejscu z próbką i bez próbki jest miarą gęstości optycznej $[10,11]$.

Badania oparte na pomiarze gęstości optycznej (densytometryczne) mają zastosowanie do określenia wysokości wad spoin. Sposób postępowania określa norma [12]. Badanie polega na porównaniu gęstości optycznej potencjalnej wady z gęstością optyczną odpowiedniego stopnia wzorca defektometrycznego (rys. 1).
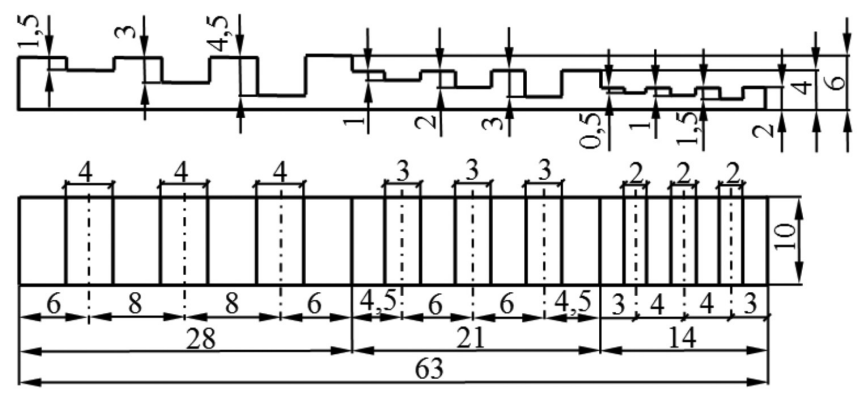

Rys. 1. Wzorzec defektometryczny schodkowo-rowkowy [12] Fig. 1. Pattern stepped-groove

Odchyłki grubości i głębokości wzorca powinny mieścić się w granicach $\pm 0,1 \mathrm{~mm}$, a odchyłki dla pozostałych wymiarów $\pm 0,2 \mathrm{~mm}$. Powinien on być również wykonany z materiału podobnego do materiału złącza badanego.

Podczas przeprowadzania badań wzorzec należy położyć obok spoiny od strony źródła promieniowania w środku badanego odcinka spoiny. Gęstość optyczną obrazu badanej wady porównuje się z gęstością optyczną odpowiedniego rowka naciętego $\mathrm{w}$ danym stopniu wzorca lub z gęstością optyczną tła. Gdy gęstości optyczne są równe, to wysokość wady jest równa głębokości danego rowka. Natomiast gdy gęstość optyczna obrazu wady jest odpowiednio równa lub większa od gęstości optycznej tła, to wysokość wady jest równa lub większa od wysokości nadlewu. Dokładną wysokość wady można ocenić na podstawie wzoru [12]:

$$
h=d \frac{D_{m}-D_{w}}{D_{m}-D_{d}}-a
$$

gdzie:

h - wysokość wady (mm),

d - grubość wzorca defektometrycznego w miejscu badanej gęstości optycznej (mm),

a - wysokość nadlewu w okolicy wady w $\mathrm{mm}$,
$D_{w}$ - gęstość optyczna obrazu wady,

$D_{m}$ - gęstość optyczna obrazu materiału rodzimego (tła),

$D_{d}$ - gęstość optyczna obrazu wzorca o grubości d położonego na materiale rodzimym.

Jeżeli $\mathrm{h}>0$, to wynik jest wysokością wady - np. wycieku, natomiast jeżeli $\mathrm{h}<0$, to wynik jest głębokością wady - np. podtopienie, brak przetopu.

\section{Ocena wiarygodności badań densytometrycznych na podstawie badań doświadczalnych}

Ocenę wiarygodności badań densytometrycznych przeprowadzono dla dwóch złączy spawanych doczołowo wykonanych z blachy o grubości $10 \mathrm{~mm}$ ze stali S355J2+N (PN-EN 10027-1:2007). Brzegi elementów łączonych spoiną zostały ukosowane na $\mathrm{V}$ i spawane metodą TIG (141 wg PN-EN ISO 4063:2011) przy użyciu drutu W 46 3 W4Si1 (PN-EN ISO 636:2016-02) w osłonie 100\% argonu (I1 wg PN-EN ISO 14175:2009). Następnie wyfrezowano rowki (rys. 2) o określonej głębokości przy linii wtopienia w celu zasymulowania niezgodności spawalniczej - podtopienia o kontrolowanej stałej głębokości. Dla jednego złącza głębokość dwóch rowków wynosiła $2 \pm 0,1 \mathrm{~mm}$, a dla drugiego 2,5 $\pm 0,1 \mathrm{~mm}$. Różne głębokości rowków posłużyły do weryfikacji oceny prawidłowości wyznaczenia wysokości zasymulowanej wady spoin (rowek) na podstawie badań densytometrycznych.

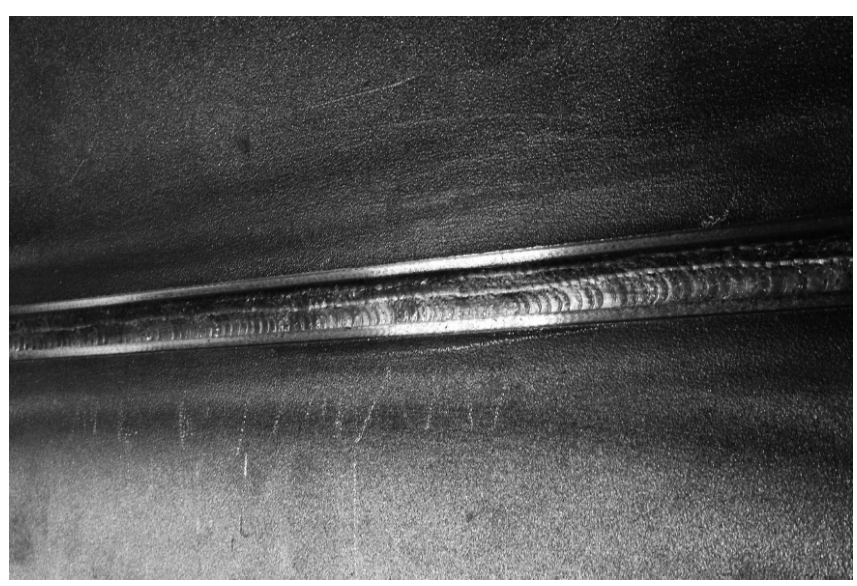

Rys. 2. Wygląd złącza spawanego z wyfrezowanymi rowkami Fig. 2. Appearance of the welded joint with milled grooves

W celu przeprowadzenia badań densytometrycznych i dokonania obliczenia na podstawie gęstości optycznej obrazu na radiogramie wysokości wady spoin symulowanej przez rowki, wykonano według normy wzorzec defektometryczny schodkowo-rowkowy przedstawiony na rysunku 3.

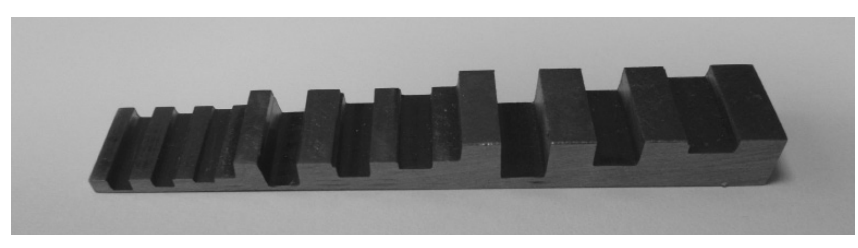

Rys. 3. Fizyczna postać wzorca defektometrycznego schodkoworowkowego

Fig. 3. The physical form of the pattern stepped-groove 
Natomiast na rysunku 4 przedstawiono złącze wraz z wzorcem przygotowane do badania radiograficznego.

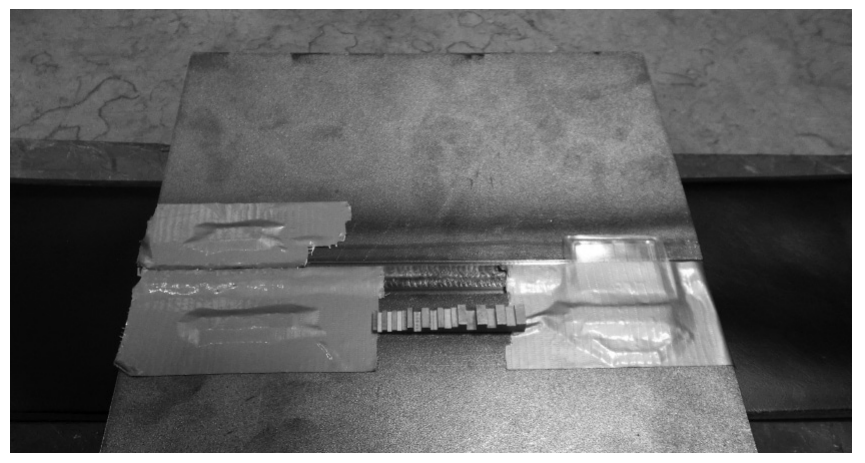

Rys. 4. Przygotowane złącze do badań radiograficznych

Fig. 4. Prepared welded joint for radiographic tests

Tablica I. Zestawienie parametrów ekspozycji na promieniowanie badanych złączy

Table I. Summary of exposure to radiation surveyed welded joint

\begin{tabular}{|c|c|}
\hline Układ badania wg PN-EN ISO 17636-1 & 1 \\
\hline Maksymalne napięcie [kV] & 180 \\
\hline Typ błony wg PN-EN ISO 17636-1 & $\mathrm{C} 4$ \\
\hline Grubość okładek [mm] & 0,1 \\
\hline Gęstość optyczna wg PN-EN ISO 17636-1 & $\geq 2.3$ \\
\hline Wskaźnik IQI wg PN-EN ISO 17636-1 & W 14 \\
\hline Odległość źródło - obiekt [f $\mathrm{min}]$ & 208 \\
\hline Odległość źródło - błona [SFD] & 700 \\
\hline Napięcie [kV] & 160 \\
\hline Natężenie [mA] & 5,6 \\
\hline Czas ekspozycji [s] & 73 \\
\hline
\end{tabular}

Do przeprowadzenia ekspozycji złączy użyto przemysłowego aparatu RTG Eresco typ 42MF4 oraz błon C4/D5 (KODAK INDUSTREX T200). W tablicy I zestawiono podstawowe parametry, przy których przeprowadzono ekspozycję na promieniowanie.

Pomiaru gęstości optycznej dokonano densytometrem WILNOS typ LCD-51. Oceny radiogramów (rys. 5) dokonano na negatoskopie KOWOLUX typ X3eco $\left(L_{\max }=199,00 \mathrm{Cd} / \mathrm{m}^{2}\right.$, $D_{\max }=4,30$ ).

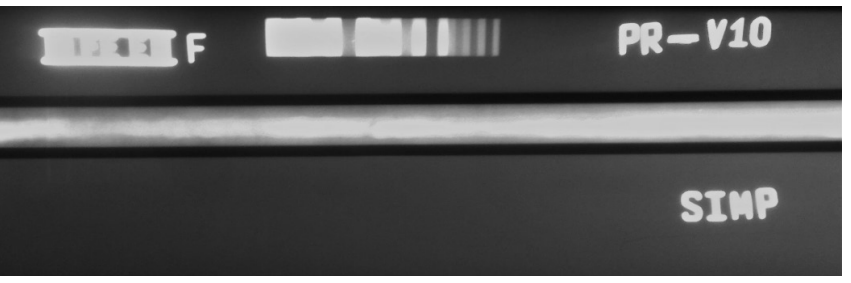

Rys. 5. Przykładowy radiogram badanego złącza

Fig. 5. Exemplary radiograph research welded joint

Na przedstawionym radiogramie widoczne są ślady wykonanych rowków oraz wzorca defektometrycznego.

W tablicy II przedstawiono zestawienie wartości pomiarów densytometrycznych, wartości niezbędnych wielkości do wykonania obliczeń, wyliczonej wysokości symulowanej wady spoin wg normy [12] (głębokości rowka h) oraz względnych różnic w \% $(\Delta \mathrm{h})$ między wyliczoną głębokością rowka a wartością nominalną. Średnia wartość gęstości optycznej obrazu wzorca $\left(D_{d}\right)$ została wyznaczona z trzech pomiarów.

Z przedstawionych wyników: $h, \Delta$ h, można odczytać dużą rozbieżność między obliczoną głębokością rowka (wysokością wady) a wartością nominalną. Jest to szczególnie widoczne przy procentowej różnicy względnej, rozbieżności sięgają prawie $45 \%$.

W celu pełniejszej interpretacji wyników i obliczeń na podstawie obliczonych wartości głębokości rowka (wysokości wady) opracowano wykresy (rys. 6), na których zilustrowano wspomniane rozbieżności obliczeń w stosunku do wartości nominalnej głębokości rowka.

Tablica II. Wyniki pomiarów i obliczeń głębokości rowka symulującego wadę spawalniczą: R1 - rowek o głębokości $2 \mathrm{~mm}$, $\mathrm{R}_{2}$ - rowek o głębokości $2,5 \mathrm{~mm}$

Table II. The results of measurements and calculations groove depth simulates welding defect: R1 - groove depth $2 \mathrm{~mm}, \mathrm{R}_{2}-\mathrm{groove}$ depth $2,5 \mathrm{~mm}$

\begin{tabular}{|c|c|c|c|c|c|c|c|c|c|c|c|c|c|}
\hline \multirow{2}{*}{ Pomiar } & \multirow{2}{*}{$\underset{[\mathrm{mm}]}{\mathrm{d}}$} & \multicolumn{2}{|c|}{$\mathrm{D}_{\mathrm{m}}$} & \multicolumn{2}{|c|}{$\mathrm{D}_{\mathrm{w}}$} & \multicolumn{2}{|c|}{$D_{d}$} & \multicolumn{2}{|c|}{$\mathrm{a}[\mathrm{mm}]$} & \multicolumn{2}{|c|}{$\mathrm{h}$ [mm] } & \multicolumn{2}{|c|}{$\Delta \mathrm{h}[\%]$} \\
\hline & & $\mathbf{R}_{1}$ & $\mathbf{R}_{\mathbf{2}}$ & $\mathbf{R}_{1}$ & $\mathbf{R}_{\mathbf{2}}$ & $\mathbf{R}_{1}$ & $\mathbf{R}_{\mathbf{2}}$ & $\mathbf{R}_{1}$ & $\mathbf{R}_{\mathbf{2}}$ & $\mathbf{R}_{1}$ & $\mathbf{R}_{2}$ & $\mathbf{R}_{1}$ & $\mathbf{R}_{\mathbf{2}}$ \\
\hline 1 & 4,5 & 3,26 & 4,25 & 3,95 & 5,08 & 1,96 & 2,41 & 0,5 & 0,7 & 2,888 & 2,73 & 44,4 & 9,2 \\
\hline 2 & 3 & 3,26 & 4,25 & 3,95 & 5,08 & 2,56 & 2,74 & 0,5 & 0,7 & 2,399 & 2,349 & 19,95 & 6,04 \\
\hline 3 & 1,5 & 3,26 & 4,25 & 3,95 & 5,08 & 2,17 & 3,21 & 0,5 & 0,7 & 1,979 & 1,897 & 1,05 & 24,12 \\
\hline 4 & 3 & 3,26 & 4,25 & 3,95 & 5,08 & 2,21 & 2,56 & 0,5 & 0,7 & 2,471 & 2,664 & 23,55 & 6,56 \\
\hline 5 & 2 & 3,26 & 4,25 & 3,95 & 5,08 & 2,45 & 3,14 & 0,5 & 0,7 & 2,204 & 2,195 & 10,2 & 12,2 \\
\hline 6 & 1 & 3,26 & 4,25 & 3,95 & 5,08 & 2,70 & 3,52 & 0,5 & 0,7 & 1,732 & 1,837 & 13,4 & 26,52 \\
\hline 7 & 1,5 & 3,26 & 4,25 & 3,95 & 5,08 & 2,61 & 3,20 & 0,5 & 0,7 & 2,092 & 2,486 & 4,6 & 0,56 \\
\hline 8 & 1 & 3,26 & 4,25 & 3,95 & 5,08 & 2,81 & 3,02 & 0,5 & 0,7 & 2,033 & 2,15 & 1,65 & 14 \\
\hline 9 & 0,5 & 3,26 & 4,25 & 3,95 & 5,08 & 2,96 & 3,75 & 0,5 & 0,7 & 1,65 & 1,93 & 17,5 & 22,8 \\
\hline
\end{tabular}



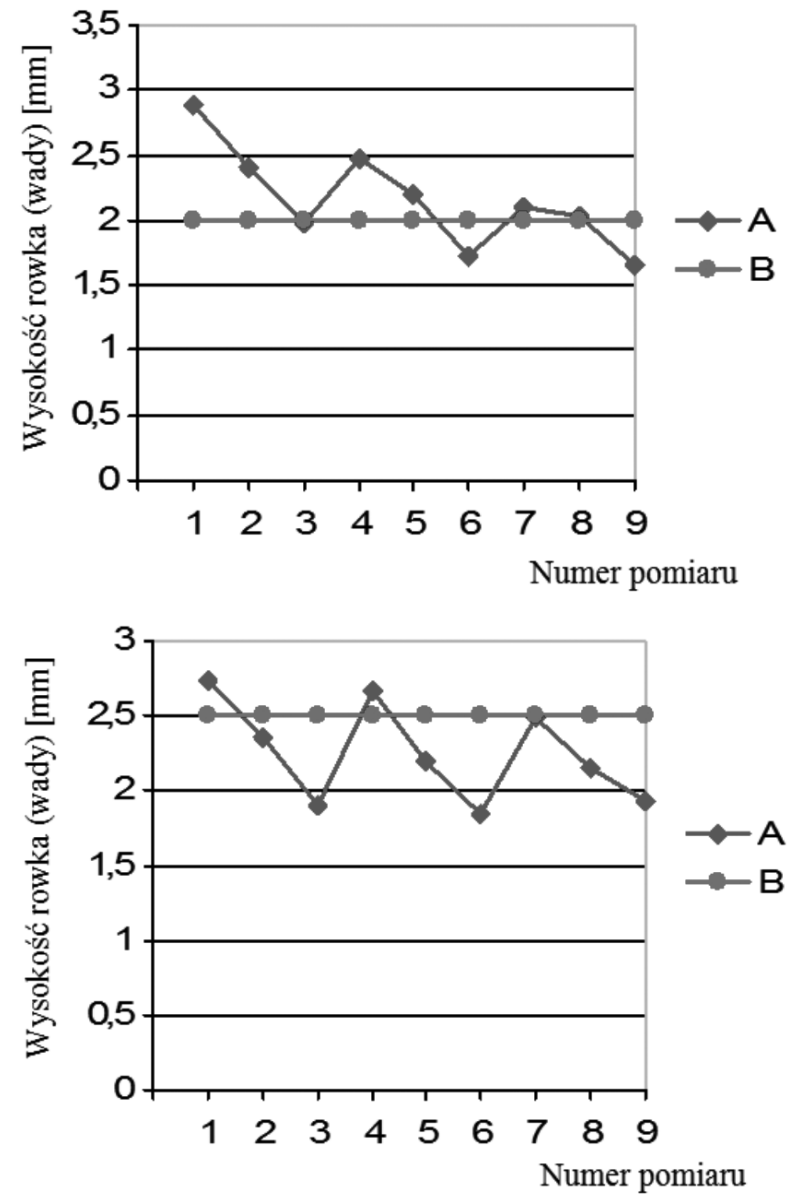

Z wykresów również można zaobserwować dużą rozbieżność obliczonych wyników (głębokości rowka) w stosunku do nominalnego wymiaru, zarówno dla rowka o głębokości $2 \mathrm{~mm}$ jak i dla rowka o głębokości 2,5 mm. Dla rowka o głębokości $2 \mathrm{~mm}$, zakres rozrzut wyników, to aż 1,238 $\mathrm{mm}$. Natomiast dla rowka o głębokości $2,5 \mathrm{~mm}$, zakres rozrzut wyników, to $0,893 \mathrm{~mm}$. Wpływ na tak dużą rozbieżność niewątpliwie ma dokładność wykonania wzorca defektometrycznego schodkowo-rowkowego oraz rowka.

Przeprowadzona ocena wiarygodności badania densytometrycznego, będącego badaniem radiograficznym wykazała dużą niejednoznaczność w określaniu głębokości rowka (wysokości wady spoiny). Stosując tę metodę, należy zwrócić szczególną uwagę na dokładność wykonania wzorca defektometrycznego oraz na wymagania jakie dane złącze ma spełniać. Jeśli wartości graniczne niezgodności spawalniczej dla danego złącza będą wyznaczały bardzo mały przedział, to będzie istniało ryzyko popełnienia błędu przy ocenie poziomu akceptacji złącza spawanego (PN-EN ISO 5817, PN-EN ISO 10675-1).

$\mathrm{Na}$ podstawie przeprowadzonej analizy wykazano również jak ważne jest właściwe planowanie badań nieniszczących w kontroli jakości złączy spawanych. Potwierdzono, że w badaniach nieniszczących należy przyjąć zespół (kombinację) metod kontroli składający się z minimum dwóch niezależnych badań stosowanych równolegle.

Rys. 6. Wykresy głębokości rowka: a) o wymiarze nominalnym $2 \mathrm{~mm}, \mathrm{~b})$ o wymiarze nominalnym 2,5 mm; A - wartość z obliczeń, B - wartość nominalna

Fig. 6. Exemplary radiograph research welded joint

\section{Podsumowanie}

Przeprowadzona ocena wiarygodności badania densytometrycznego wykazała dużą niejednoznaczność w określaniu wysokości wady spoiny (na przykładzie głębokości rowka). Metoda ta, która jest jedną z metod radiograficznych, jest metodą badań zależną od wielu czynników. Stosując tę metodę, należy zwrócić szczególną uwagę na dokładność wykonania wzorca defektometrycznego. Ważnym czynnikiem jest również właściwa interpretacja radiogramu, co jest z kolei ściśle związane z odpowiednimi - bardzo dużymi - kwalifikacjami osób odpowiedzialnych za wykonywanie badań.

Bardzo istotnym elementem w badaniach jakości spoin jest przyjęcie określonych standardów postępowania w przyjmowaniu różnych metod badań nieniszczących i ich wykonywania.

\section{Literatura}

[1] Czuchryj J.: Badania złączy spawanych według norm europejskich. Systematyka i przyczyny powstawania wad w złączach spawanych, Wyd. III, Biuro Gamma, Warszawa 2003.

[2] Czuchryj J.: Kontrola jakości prac spawalniczych, Wydawnictwo KaBe, Krosno 2002.

[3] Klimpel A.: Kontrola i zapewnienie jakości w spawalnictwie, Tom 1, Wydawnictwo Politechniki Śląskiej, Gliwice 1998.

[4] Gourd L. M.: Podstawy technologii spawalniczych, WNT, Warszawa 1997.

[5] Bęczkowski R.: Analiza występowania niezgodności spawalniczych w podstawach wież wiatrowych, Przegląd Spawalnictwa, nr 5/2016, s. 93-96.

[6] Bęczkowski R., Gucwa M.: Plany jakości przy wytwarzaniu konstrukcji stalowych, Przegląd Spawalnictwa, nr 5/2015, s. 103-105.
[7] Brózda J., Czuchryj J.: Kontrola radiograficzna złączy spawanych. Poradnik, Biuro Gamma, Warszawa 2006.

[8] Mizerski J.: Spawanie. Wiadomości podstawowe, Wydawnictwo REA, Warszawa 2011

[9] Wojas M.: Potwierdzanie kompetencji personelu badań nieniszczących według standardów światowych, Przegląd Spawalnictwa, nr 12/2015, s. $35-40$.

[10] Ferenc K. J.: Spawalnictwo, WNT, Warszawa 2007.

[11] Mistur I., Czuchryj J.: Metody spawania oraz sposoby oceny jakości złączy spawanych, Wydawnictwo KaBe, Krosno 2005.

[12] PN-87/M-69776: Spawalnictwo, Określanie wysokości wad spoin na podstawie gęstości optycznej obrazu na radiogramie. 


\section{Podsumowanie}

W artykule przedstawiono możliwości binarnej analizy obrazu uzyskanego z tomografu ultradźwiękowego dla przebadanych elementów betonowych dostępnych jednostronnie przy pomocy programu Wolfram Mathematica. Na podstawie "obróbki" uzyskanych z badań danych cyfrowych wykonano zobrazowania, które posłużyły do dalszej analizy. Analiza taka daje większe możliwości dokładniejszej interpretacji otrzymanych wyników badań, między innymi poprzez zbudowanie histogramu w 3D, czyli przedstawienie danego obrazu w postaci funkcji jasności. Należy podkreślić, że w pracy przedstawiono jedynie kilka z wielu możliwych operacji, jakich można dokonać przy użyciu programu Wolfram Mathematica do binarnej analizy obrazu z tomografii ultradźwiękowej i są one przyczynkiem do dalszych prac i rozwijania tego sposobu analizy wyników badań.

\section{Literatura}

[1] Schabowicz K., Methodology for non-destructive identification of thickness of unilaterally accessible concrete elements by means of state-of-the art acoustic techniques, Journal of Civil Engineering and Management, 19 (3) (2013), pp. 325-334.

[2] Schabowicz K., Modern acoustic techniques for testing concrete structures accessible from one side only, 15, 2015, pp. 1149-1159.

[3] Schabowicz K., Ultrasonic tomography - The latest nondestructive technique for testing concrete members - Desription, test methodology, application axample, Archives of Civil and Mechanical Engineering, 14, 2014, pp. 295-303.

[4] Schabowicz K., Suvorov V.A., Nondestructive testing of a bottom surface and construction of its profile by ultrasonic tomography, Russian Journal of Nondestructive Testing, 50, 2014, pp. 109-119.

[5] Tadeusiewicz R., Korohoda P., Komputerowa analiza i przetwarzanie obrazów, Wydawnictwo Politechniki Wrocławskiej, 1990.

[6] Informacja ze strony www.acsys.ru

[7] Tomasz Gorzelańczyk, Krzysztof Schabowicz: Nieniszczące badania płyt włóknisto-cementowych metodą dielektryczną, Przegląd Spawalnictwa, 11/2014, s. 24-27.

[8] Jacek Szelążek: Próbki szklane grawerowane laserowo jako wzorce dwójłomności w badaniach ultradźwiękowych, Przegląd Spawalnictwa, 11/2014, s. 11-13. 